Article

\title{
Exploring New Extractive Phases for In-Tube Solid Phase Microextraction Coupled to Miniaturized Liquid Chromatography
}

\author{
Pascual Serra-Mora, Paola García-Narbona, Jorge Verdú-Andrés, Rosa Herráez-Hernández *iD \\ and Pilar Campíns-Falcó *D
}

MINTOTA Research Group, Department of Analytical Chemistry, Faculty of Chemistry, University of Valencia, Dr Moliner 50, 46100 Burjassot, Valencia, Spain; pascual.serra@uv.es (P.S.-M.); paganar@alumni.uv.es (P.G.-N.); Jorge.Verdu@uv.es (J.V.-A.)

* Correspondence: rosa.herraez@uv.es (R.H.-H.); pilar.campins@uv.es (P.C.-F.); Tel.: +34-96-354-4978 (R.H.-H.); +34-96-354-3002 (P.C.-F.)

Received: 30 December 2018; Accepted: 14 February 2019; Published: 25 February 2019

check for updates

\begin{abstract}
In-tube solid-phase microextraction (IT-SPME) coupled on-line to miniaturized liquid chromatography (LC) has emerged as a powerful tool to address a variety of analytical problems. However, in order to expand its applicability, the development of new sorbents that enhance the efficiency and specificity of the extraction is highly desirable. In this respect, the employment of capillary columns coated with sorbents functionalized with nanoparticles (NPs) replacing the loop of the injection valve (in-valve IT-SPME) is one of the most attractive options. In this work, polymers of tetraethyl orthosilicate (TEOS) and trimethoxyethylsilane (MTEOS) modified with $\mathrm{SiO}_{2}$ and $\mathrm{TiO}_{2}$ NPs have been synthetized and used for the extraction of a variety of water pollutants, using both Capillary-LC and Nano-LC. Compounds with different chemical structures and polarities such as the artificial sweetener saccharine, the polycyclic aromatic hydrocarbons (PAHs) naphthalene and fluoranthene, and some phenylurea and organophosphorous herbicides have been used as target analytes. The extraction efficiencies found with the synthetized capillaries have been compared to those obtained with commercially available capillaries coated with polydiphenyl-polydimethylsiloxane (PDMS), nitroterephthalic acid modified polyetilenglicol (FFAP), and polystyrene-divinylbenzene (PS-DVB) phases. The results obtained in this preliminary study showed that, although PS-DVB phase has the strongest affinity for compounds with two or more aromatic rings, the extraction with TEOS-MTEOS coatings modified with NPs is the best option for a majority of the tested compounds. Examples of application are given.
\end{abstract}

Keywords: in-tube solid phase microextraction (IT-SPME); $\mathrm{SiO}_{2}$ nanoparticles; $\mathrm{TiO}_{2}$ nanoparticles; capillary liquid chromatography; nano-liquid chromatography

\section{Introduction}

High extraction efficiencies, although always desirable, are essential in techniques that integrate on-line sample preparation and LC. This is the case of IT-SPME. In this modality of microextraction, the extractive phase is typically the coating of a capillary column used in replacement of the injection valve inert loop, so that the extraction takes place simultaneously with the sample loading. A subsequent change in the valve position allows the desorption and transfer of the retained analytes to the separative column by means of the mobile-phase. Today, IT-SPME is a well-established technique that has been successfully used in many fields of applications [1-3]. This technique is especially well-suited for miniaturized LC systems such as Capillary-LC (Cap-LC) and Nano-LC. This is because relatively large sample volumes can be loaded into the extractive capillary for on-line analyte enrichment overcoming 
the lack of sensitivity derived from the fact that only low volumes of the samples can be injected in miniaturized LC systems. The utility of IT-SPME in Cap-LC has been demonstrated through a wide variety of applications mainly in the environmental and biomedical fields [4-7] and, very recently, IT-SPME has been coupled to Nano-LC [8,9]. Substantial progress in the area can be expected through the development of new sorbents for the improved extraction of a wide variety of analytes and matrices.

In recent years, several materials have been used as sorbents for extraction and microextraction of organic compounds. Successful examples have been reported using a variety of polymers, ionic liquids, metal organic frameworks, covalent organic frameworks and different types of NPs such as carbon, metal or metal oxide NPs [10,11]. Among them, nanostructured sorbents have gained significant interest due to their inherent advantages, especially their high specific surface for interaction with the target compounds and the possibility of increasing the affinity for the analytes through a variety of interactions [12,13].

As regards solid-phase microextraction, most of the efforts made have been focused on the development of coatings for fibres [14], whereas only a few sorbents with nanomaterials for IT-SPME have been reported so far. Examples are the employment of titanium [15] or silica [16] capillaries chemically treated to produce nanostructured internal surfaces. From a different perspective, a polymeric phase can be reinforced with NPs. For example, in previous studies, we demonstrated that the functionalization of commercial polydimethylsiloxane (PDMS) coated columns with different types of carbon nanotubes (CNTs) may improve the extraction efficiency for a variety of compounds such as drugs and pollutants [5,6]. More recently, polymeric coatings of tetraethyl orthosilicate (TEOS) and trimethoxyethylsilane (MTEOS) were functionalized with $\mathrm{SiO}_{2} \mathrm{NPs}$ and used for the extraction of herbicides of different polarities. The presence of $\mathrm{SiO}_{2} \mathrm{NPs}$ increased the extraction efficiency for most of the compounds tested [7].

As a continuation of those studies, in the present work we have synthetized a TEOS-MTEOS polymer modified with $\mathrm{TiO}_{2}$ NPs. This type of NPs has been extensively investigated in SPME with fibres and other forms of microextraction [17]. However, their application to IT-SPME is still very limited [15]. The new TEOS-MTEOS/ $\mathrm{TiO}_{2}$ NPs composite has been tested for the IT-SPME of variety of organic pollutants, and the results have been compared with those obtained with the polymer modified with $\mathrm{SiO}_{2} \mathrm{NPs}$, as well as with different commercially available capillaries coated with polymers. The commercial capillaries tested were TRB 35, FFAP and PS-DVB, with coatings of $35 \%$ polydiphenyl-65\% polydimethyl siloxane (PDMS), nitroterephthalic acid modified poly (ethyleneglycol) (PEG) and polystyrene-divinylbenzene (PS-DBV), respectively.

The proposed phases were tested for different types of substances. IT-SPME coupled to Cap-LC with fluorescence detection was used for the analysis of compounds with aromatic rings in their chemical structure, more specifically the artificial sweetener saccharine (emerging pollutant), and the PAHs naphthalene and fluoranthene, all of them with native fluorescence. IT-SPME coupled to Nano-LC with UV detection has been used for the study of a variety of phenylurea and organophosphorous herbicides. The chemical structures of the tested compounds and their respective octanol/water partition coefficients $\left(\mathrm{K}_{\mathrm{ow}}\right)$ are listed in Table 1. 
Table 1. Chemical structures and $\log \mathrm{K}_{\mathrm{ow}}$ of the tested compounds.

Compound Laccharine

\section{Materials and Methods}

\subsection{Chemicals}

All the reagents used throughout the study were of analytical grade. Saccharin, fenitrothion bifenox, TEOS, MTEOS, PEG, $\mathrm{SiO}_{2}$ NPs (5-15 nm), $\mathrm{TiO}_{2} \mathrm{NPs}(21 \mathrm{~nm}), \mathrm{NaOH}$ and $\mathrm{NH}_{4} \mathrm{OH}$ were obtained from Sigma-Aldrich (St. Louis, MO, USA). Naphthalene, fluoranthene, fluometuron, isoproturon, metobromuron, linuron, fenthion and fenamiphos were obtained from Dr. Ehrenstorfer (Augsburg, Germany). Acetone was obtained from Romil (Cambridge, UK). Acetonitrile was of HPLC grade (MWR Radnor, Philadelphia, PA, USA).

Stock standard solutions of the analytes $(100 \mu \mathrm{g} / \mathrm{mL})$ were prepared by dilution of the commercial reagents in acetonitrile and kept at $-20{ }^{\circ} \mathrm{C}$ until use. Working solutions were prepared by dilution of the stock solutions with ultrapure water. 


\subsection{Apparatus and Chromatographic Conditions}

\subsubsection{Cap-LC}

The chromatographic system consisted of an isocratic capillary pump, a high-pressure six-port valve (Rheodyne, Rohnert Park, CA, USA), a LC-Net II/ADC interface and a programmable fluorescence detector (Jasco Corporation Micro 21PU-01, Tokyo, Japan). The detector was coupled to a data system (Jasco ChromNAV Chromatography Data System) for data acquisition and calculation. The excitation/emission wavelengths were $235 \mathrm{~nm} / 335 \mathrm{~nm}, 265 \mathrm{~nm} / 475 \mathrm{~nm}$ and $250 \mathrm{~nm} / 440 \mathrm{~nm}$ for naphthalene, fluoranthene and saccharine, respectively.

A Zorbax SB-C18 $(150 \mathrm{~mm} \times 0.5 \mathrm{~mm}$ i. d., $5 \mu \mathrm{m})$ column was used for the separation of the analytes. The mobile-phase was a mixture of acetonitrile-water in isocratic mode, and the flow rate was $25 \mu \mathrm{L} / \mathrm{min}$. Under optimized conditions, the run times were $8 \mathrm{~min}$ and $10 \mathrm{~min}$ the analysis of saccharine and the PAHs, respectively. Solvents were filtered through $0.22 \mu \mathrm{m}$ nylon membranes (Teknokroma, Barcelona, Spain) and degassed in an ultrasonic bath before use.

\subsubsection{Nano-LC}

Chromatographic analysis was performed using a Agilent 1260 Infinity nanoLC chromatograph equipped with a quaternary nano-pump, a six port micro-scale manual injector (Rheodyne), and a UV-Vis diode array detector with $80 \mathrm{~nL}$ nanoflow cell (Agilent, Waldbronn, Germany). The detector was coupled to a data system (Agilent, ChemStation) for data acquisition and treatment. The analytical signal was recorded between $190 \mathrm{~nm}$ and $400 \mathrm{~nm}$ and monitored at $254 \mathrm{~nm}$. A Zorbax 300 SB C18 (50 $\mathrm{mm} \times 0.075 \mathrm{~mm}$ i. d., $3.5 \mu \mathrm{m}$ particle size) analytical column (Agilent) was used for separation.

The mobile phase was a mixture of water-acetonitrile in gradient elution mode. The percentage of acetonitrile in the mobile phase was linearly increased from $30 \%$ at $0-2 \mathrm{~min}$, to $100 \%$ at $8 \mathrm{~min}$, and then kept constant until $13 \mathrm{~min}$; finally, the acetonitrile percentage was linearly decreased to reach a percentage of $30 \%$ at $18 \mathrm{~min}$, and maintained constant until the end of the run; the run time was $30 \mathrm{~min}$. The flow rate was $0.5 \mu \mathrm{L} / \mathrm{min}$. All solvents were filtered through $0.22 \mu \mathrm{m}$ nylon membranes (Teknokroma) before use.

\subsection{Preparation of the TEOS-MTEOS Coated Capillaries}

The TEOS-MTEOS coated capillaries were prepared from segments of fused silica capillaries of $30 \mathrm{~cm}$-length and $320 \mu \mathrm{m}$ i. d. or 15-cm length and $75 \mu \mathrm{m}$ i. d. (Análisis Vínicos, Tomelloso, Spain) for the Cap-LC and Nano-LC systems, respectively. The procedure used to synthetize the $\mathrm{SiO}_{2} \mathrm{NPs}$ reinforced coatings was previously described in detail in [8]. Briefly, the internal walls of the silica capillaries were first activated by flushing through them $1 \mathrm{M} \mathrm{NaOH}$ for $4 \mathrm{~h}$ at $40{ }^{\circ} \mathrm{C}$ followed by $0.1 \mathrm{M}$ $\mathrm{HCl}$ for $30 \mathrm{~min}$ at room temperature; next, the capillaries were heated at $60{ }^{\circ} \mathrm{C}$ for $3 \mathrm{~h}$, and finally flushed with water and dried with air. For coating of the capillaries, a mixture of $65 \mathrm{mg}$ of PEG, $100 \mu \mathrm{L}$ of TEOS (93 mg), $100 \mu \mathrm{L}$ MTEOS (90 mg), $50 \mu \mathrm{L}$ of water, $2 \mathrm{~mL}$ of $0.1 \mathrm{M} \mathrm{NH}_{4} \mathrm{OH}$ (catalyst) and the $\mathrm{SiO}_{2}$ or the $\mathrm{TiO}_{2}$ NPs were placed in a glass vial; the amount of NPs in the resulting mixture was $0.05 \mathrm{mg} / \mathrm{mL}$. After vortexing for $1 \mathrm{~min}$, the resulting homogenous dispersion was used to fulfill the preconditioned capillaries. Then, the capillaries were heated at $40{ }^{\circ} \mathrm{C}$ for $2 \mathrm{~h}$ and aged overnight $(14-15 \mathrm{~h})$ at $120^{\circ} \mathrm{C}$.

\subsection{IT-SPME Conditions}

For IT-SPME coupled to Cap-LC, segments of different commercially available GC columns of $30 \mathrm{~cm}$ length and $320 \mu \mathrm{m}$ i. d. were used as extractive capillaries for IT-SPME, namely TRB 35, ZB-FFAP and PS-DVB, and the results were compared with those obtained with the synthesized TEOS-MTEOS reinforced with $\mathrm{SiO}_{2}$ or $\mathrm{TiO}_{2}$ NPs capillaries. The TRB 35 capillaries, coated with a 35\% diphenyl-65\% PDMS, 3 um coating thickness, were purchased from Teknokroma (Barcelona, Spain). The ZB-FFAP 
(nitroterephthalic acid modified PEG), $1 \mu \mathrm{m}$ film thickness, was supplied from Phenomenex (Torrance, CA, USA). The PS-DBV, $20 \mu \mathrm{m}$ coating thickness, capillary was obtained from Agilent Technologies.

The extractive capillaries were used as the loop of the six-port injection valves. Samples were manually loaded into capillaries using a $500 \mu \mathrm{L}$ precision syringe; then, the valve was changed to the injection position, so the analytes retained in the capillary were desorbed with the mobile-phase and transferred to the analytical column for separation and detection. For connecting the extractive capillaries to the valve $2.5 \mathrm{~cm}$ sleeve of $1 / 6$ i. $\mathrm{n}$. (340-380 $\mu \mathrm{m}$ i. d.) polyether ether ketone (PEEK) tubing, $1 / 6$ i. n. PEEK nuts and ferrules were used. All assays were made by triplicate at ambient temperature.

\subsection{Analysis of Water and Soil samples}

Samples were collected at the Comunitat Valenciana region (East Spain). Water samples were river water (Xúquer river, coordinates: $39.151469,-0.239126$ ) and ditch water (coordinates: 39.500606 , -0.384912 ). Once collected, samples were kept at $4{ }^{\circ} \mathrm{C}$, and filtered through $0.22 \mu \mathrm{m}$ nylon filters (Teknokroma) just before their analysis. Aliquots of $200 \mu \mathrm{L}$ of the filtered samples were processed by Cap-LC under the optimized conditions.

For the analysis of soil, a soil sample collected from agricultural zone was dried at ambient temperature and then sieved $(\leq 2 \mathrm{~mm})$. Accurately weight portions $(0.3 \mathrm{~g})$ were spiked with a mixture of naphthalene and fluoranthene at concentrations of 15 and $12 \mu \mathrm{g} / \mathrm{g}$, respectively, and extracted with $1.3 \mathrm{~mL}$ of acetone at $30^{\circ} \mathrm{C}$ in an ultrasonic bath for $30 \mathrm{~min}$. After centrifugation at $5000 \mathrm{rpm}$ for $10 \mathrm{~min}$, the supernatant was removed and filtered with $0.22 \mu \mathrm{m}$ nylon filters (Teknokroma). The filtered extracts were evaporated to dryness and then reconstituted with $1 \mathrm{~mL}$ of ultrapure water. Finally, $200 \mu \mathrm{L}$ of the reconstituted extracts were processed by under the optimized conditions. All assays were made by triplicate at ambient temperature.

\section{Results}

\subsection{IT-SPME Coupled to Cap-LC}

\subsubsection{Mobile Phase Composition}

Different extractive phases were evaluated for the extraction of three fluorescent compounds differenig in the number of benzene rings in their structure, sacharine, naphtalene and fluoranthene, with 1, 2 and 4 rings, respectively (see Table 1). Capillary columns with different kinds of coatings are commercially available which are compatible with the dimensions of Cap-LC. Among them, in this study columns with coatings containing phenyl groups were selected, as these phases have proved to be effective in the retention of aromatic compounds via $\pi-\pi$ interactions [7]. Capillary columns coated with PDMS modified with diphenyl groups (TRB-35), PEG modified with nitroterephtalic acid (FFAP) and polystyrene-divinylbenzene (PS-DVB) were tested, and the results were compared with those obtained with the TEOS-MTEOS reinforced with the $\mathrm{SiO}_{2}$ or $\mathrm{TiO}_{2}$ NPs coated capillaries.

Preliminary assays carried out under a variety of conditions demonstrated that not only the extraction efficiencies (evaluated as the corresponding peak areas) but also the retention times and peak shapes were highly dependent on the composition of the mobile-phase delivered though the capillary for the desorption of the analytes. For example, saccharine could be rapidly desorbed and transferred from all the capillaries tested even when water was used as the mobile phase, which can be explained by its high polarity (see Table 1). In contrast, when eluents with high percentages of water were used for fluoranthene (the most apolar compound) the desorption from some capillaries did not take place within suitable times $(<5 \mathrm{~min})$ and the resulting peaks were too wide, particularly with the PS-DVB coated capillary. For this reason, and in order to study separately the extraction efficiency from the chromatographic separation, the analytical column was removed from the system (the injection valve was directly connected to the detector). The eluent compositions selected were 
$100 \%$ water for saccharine in the TRB, FFAP and PS-DVB columns, $100 \%$ acetonitrile for fluoranthene in the PS-DVB capillary, and 50:50 for the rest of assays.

\subsubsection{Study of the Extraction Efficiency}

The extraction efficiency for the different capillaries tested was studied by processing increasing volumes of standard solutions of the analytes $(50-400 \mu \mathrm{L})$, under the elution conditions indicated above and without the chromatographic column. Although the absolute recoveries were not obtained, the efficiency of the different capillaries tested was compared though the measurement of the peak areas obtained for the target compounds with them [5-8]. The peak areas obtained for the three compounds tested are depicted in Figure 1.

(a)

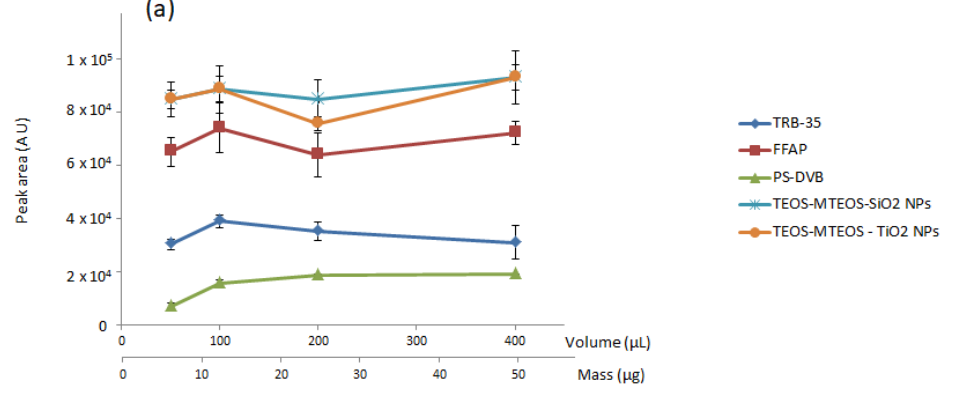

(b)
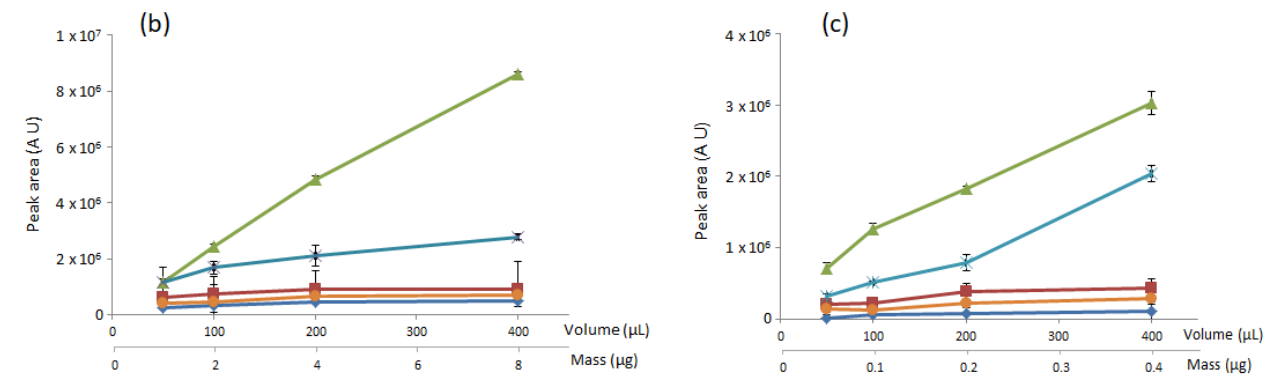

Figure 1. Effect of the sample volume (or mass of analyte introduced into the system) on the responses obtained with the different extractive capillary coatings tested for (a) saccharine $(125 \mu \mathrm{g} / \mathrm{mL})$, (b) naphthalene $(20 \mu \mathrm{g} / \mathrm{mL})$ and $(\mathbf{c})$ fluoranthene $(1 \mu \mathrm{g} / \mathrm{mL})$.

As observed from the above figure, the results obtained for saccharine were significantly different to those observed for naphthalene and fluoranthene. In all of the extractive phases tested, increasing the sample volume from $50 \mu \mathrm{L}$ to $100 \mu \mathrm{L}$ led to an increment of the peak areas of saccharine, but a further increment of the sample volume did not increase the responses. In contrast, the peak areas registered for naphthalene and fluoranthene increased as the volume of sample processed was increased within the tested interval. For the two compounds, the increment of peak areas was particularly marked with the capillaries that provided the highest analyte responses, PS-DVB and TEOS-MTEOS modified with $\mathrm{SiO}_{2}$ NPs; with these two extractive phases a nearly linear relationship between the sample volume and the peak areas was observed. For the rest of the capillaries, the increment was much more modest.

For a given sample volume, highest peak areas were obtained for saccharine with the TEOS-MTEOS capillaries modified with $\mathrm{SiO}_{2}$ and $\mathrm{TiO}_{2} \mathrm{NPs}$; no significant differences between these two capillaries were found. This suggests that the hydrogen bonding and dipole-dipole interactions that can be established between the NPs and the amino groups of the analyte are the predominant mechanisms of interaction between the extractive coatings and the analyte molecules. Among the phases with aromatic rings, the FFAP coated capillary provided the highest responses. This can be explained by the electrostatic interactions that can be established between the amino group of the analyte and the nitro groups of the nitroterephthalic acid coating (with positive charge on the nitrogen and negative on the oxygen atoms). 
Naphthalene and fluoranthene are expected to interact with the TEOS-MTEOS extractive phase mainly by hydrophobic interactions, and also by $\pi-\pi$ interactions with the TRB, FFAP and PS-DVB phases. As observed from Figure 1, the PS-DVB provided much higher extraction efficiencies than the TRB and FFAP capillaries. This can be explained by differences on the film thickness, which was much higher for the PS-DVB. In fact, even the TEOS-MTEOS $\mathrm{SiO}_{2}$ NPs reinforced polymer coating provided higher responses than the TRB and FFAP coated capillaries. As regards the two types of particles

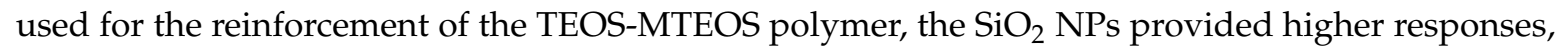
which suggested that the resulting composite had a higher specific area for interaction, as neither naphthalene nor fluoranthene have functional groups capable of establishing interactions other than hydrophobic interactions.

\subsubsection{Reproducibility and Specificity}

In order to study the reproducibility, three consecutive injections of the tested compounds were affected in the chromatographic system (with the separative column placed between the IT-SPME device and the detector) and using a sample volume of $200 \mu \mathrm{L}$. As an example, in Figure 2a are shown the chromatograms obtained for naphthalene and fluoranthene. The relative standard deviations (RSDs) were calculated from the peak areas measured for each compound ((standard deviation/mean area) $\times 100$ ). The values found with the synthetized capillaries are summarized in Table 2 , which also shows the values obtained for the commercial capillary that provided best extraction efficiency for each compound.

Table 2. Reproducibility obtained by IT-SPME-Cap-LC with the trimethoxyethylsilane (TEOS-MTEOS) capillaries functionallized with nanoparticles (NPs) and the commercial capillary that gave the best extraction rate for each compound $(n=3)$; volume of sample processed, $200 \mu \mathrm{L}$.

\begin{tabular}{|c|c|c|c|}
\hline Compound & Concentration $(\mu \mathrm{g} / \mathrm{mL})$ & Extractive Phase & RDS (\%) \\
\hline Saccharine & 125 & $\begin{array}{c}\text { TEOS-MTEOS } / \mathrm{SiO}_{2} \mathrm{NPs} \\
\text { TEOS-MTEOS } / \mathrm{TiO}_{2} \text { NPs } \\
\text { FFAP }\end{array}$ & $\begin{array}{l}6 \\
4 \\
9\end{array}$ \\
\hline Naphthalene & 20.0 & $\begin{array}{c}\text { TEOS-MTEOS } / \mathrm{SiO}_{2} \mathrm{NPs} \\
\text { TEOS-MTEOS } / \mathrm{TiO}_{2} \text { NPs } \\
\text { PS-DVB }\end{array}$ & $\begin{array}{l}4 \\
9 \\
8\end{array}$ \\
\hline Fluoranthene & 1.0 & $\begin{array}{c}\text { TEOS-MTEOS } / \mathrm{SiO}_{2} \mathrm{NPs} \\
\text { TEOS-MTEOS/TiO } 2 \text { NPs } \\
\text { PS-DVB }\end{array}$ & $\begin{array}{l}4 \\
7 \\
2\end{array}$ \\
\hline
\end{tabular}

The results of Table 2 show that the synthetized TEOS-MTEOS reinforced with NPs capillaries provided reproducibility suitable and comparable to that achieved with commercial capillaries. No significant differences on the reproducibility obtained between the two synthetized capillaries were found.

The specificity was also tested for two different matrices of interest in the environmental field, in order to investigate whether matrix components could interfere with the identification or quantification of the analytes. The samples selected were water (ditch and river water) and the extract obtained from a soil sample $(0.3 \mathrm{~g})$ treated with $1.2 \mathrm{~mL}$ of acetone in an ultrasonic bath, and the PAHs naphthalene and fluoranthene were selected as model compounds. The water samples were filtered before being loaded into the chromatographic system, whereas the extract of soil was evaporated to dryness, and then reconstituted with water and filtered before being processed. In Figure $2 b$ are shown the chromatograms obtained for some of the samples assayed using the optimized IT-SPME conditions (PS-DVB capillary). 
(a)

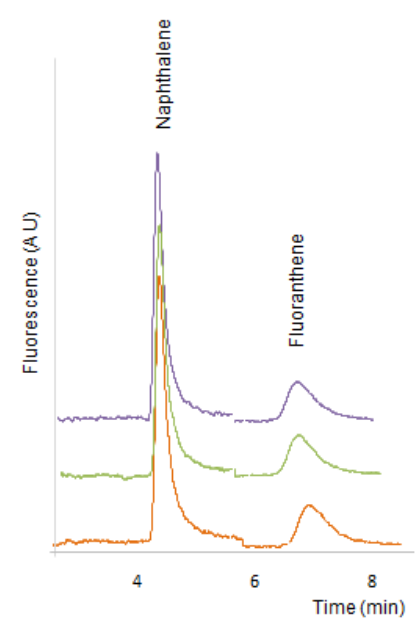

(b)

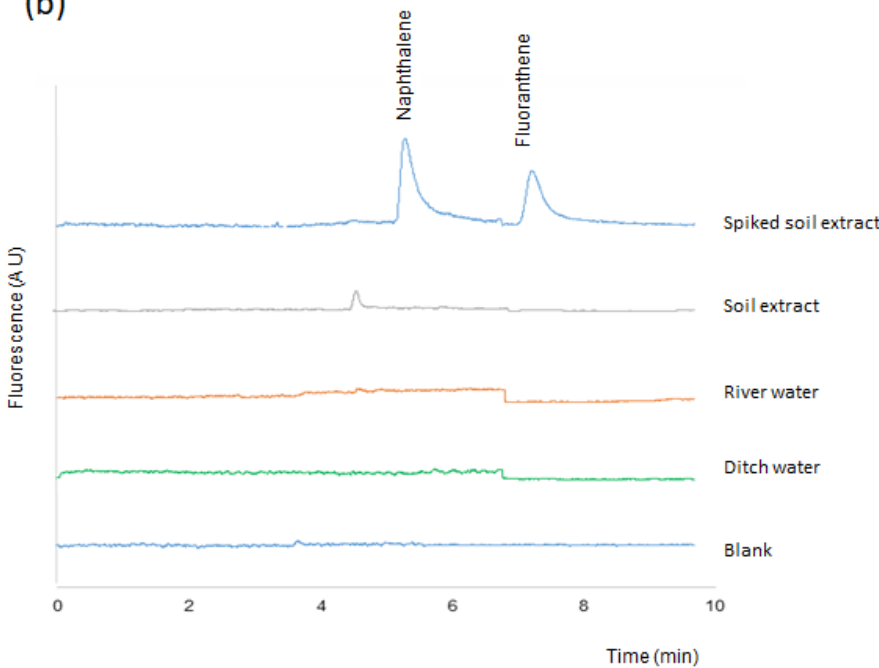

Figure 2. Chromatograms obtained under optimized conditions for (a) three successive injections of a standard solution containing $2.5 \mu \mathrm{g} / \mathrm{mL}$ of naphthalene and $0.18 \mu \mathrm{g} / \mathrm{mL}$ of fluoranthene; (b) a blank (nanopure water), ditch and river water, and for the extract obtained for a soil sample, and the same soil spiked with naphthalene and fluoranthene. Volume of working solution processed, $200 \mu \mathrm{L}$.

As observed in the above figure, no significant differences between the registers obtained for nanopure water and for the water samples were observed. Thus, the specificity for this kind of samples was considered satisfactory. A minor peak was observed in the solid extract; the intensity of such peak was much lower in the spiked soil sample. These differences could most probably be minimized by reducing the soil particle size. Nevertheless, as the aforementioned peak eluted at a retention time different to those of the analytes, it was concluded that the specificity for the solid extracts was also suitable.

\subsection{IT-SPME Coupled to Nano-LC}

The number of capillaries with suitable dimensions for coupling IT-SPME to Nano-LC is still very low. For this reason, only the extraction efficiency of TEOS-MTEOS modified with $\mathrm{SiO}_{2} \mathrm{NPs}_{\mathrm{N}}$ and $\mathrm{TiO}_{2}$ NPs could be tested and compared. Different herbicides were tested as the target compounds (Table 1).

Preliminary tests showed that the desorption of the extracted analytes from the capillaries could be effected under a wide variety of eluent compositions; therefore, this study was carried out with the IT-SPME connected to the analytical column. As for Cap-LC, an increment volume had a positive effect on peak areas for a majority of the tested compounds; increasing responses were observed up to sample volumes of $500 \mu \mathrm{L}$, although a further increment to $750 \mu \mathrm{L}$ had no a positive effect on peaks areas. This is illustrated, in Figure 3, which shows the effect of the sample volume on peak areas when processing different sample volumes with the $\mathrm{TiO}_{2} \mathrm{NPs}$ modified coating. 


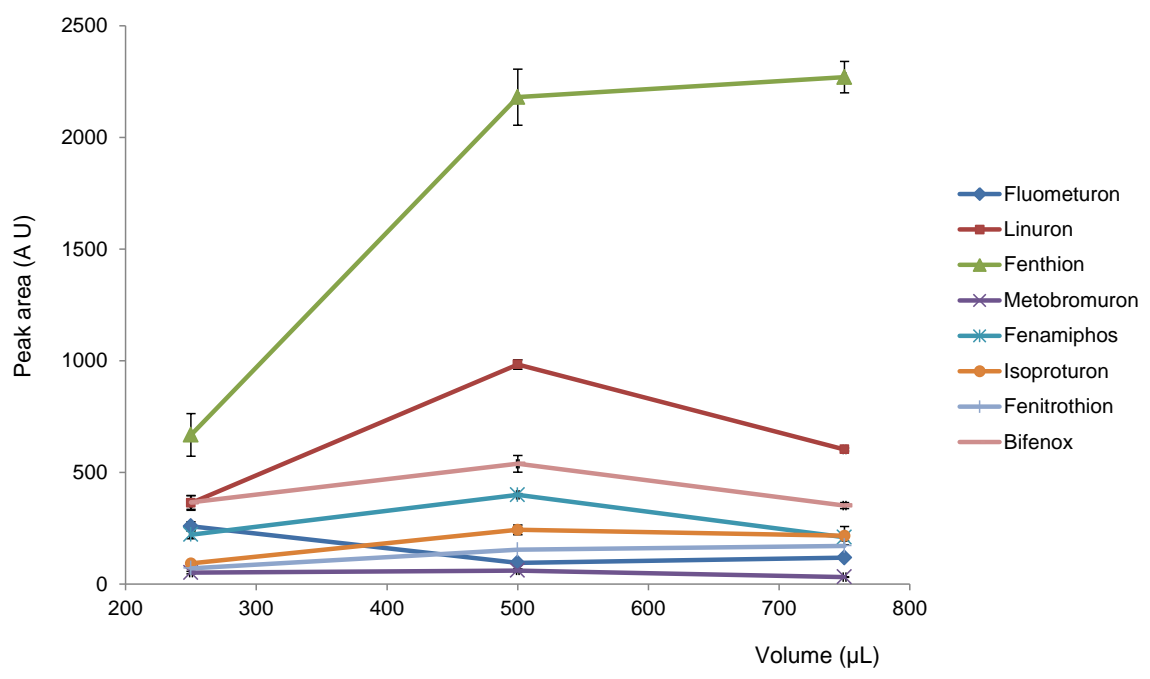

Figure 3. Variation of the peak areas with the sample volume with the TEOS-MTEOS extractive phase reinforced with $\mathrm{TiO}_{2}$ NPs. Concentration assayed, $25 \mathrm{ng} / \mathrm{mL}$ for linuron and $10 \mathrm{ng} / \mathrm{mL}$ for the rest of compounds.

Consequently, a sample volume of $500 \mu \mathrm{L}$ was selected to compare the extraction efficiency of the two capillaries tested. The results obtained are depicted in Figure 4.

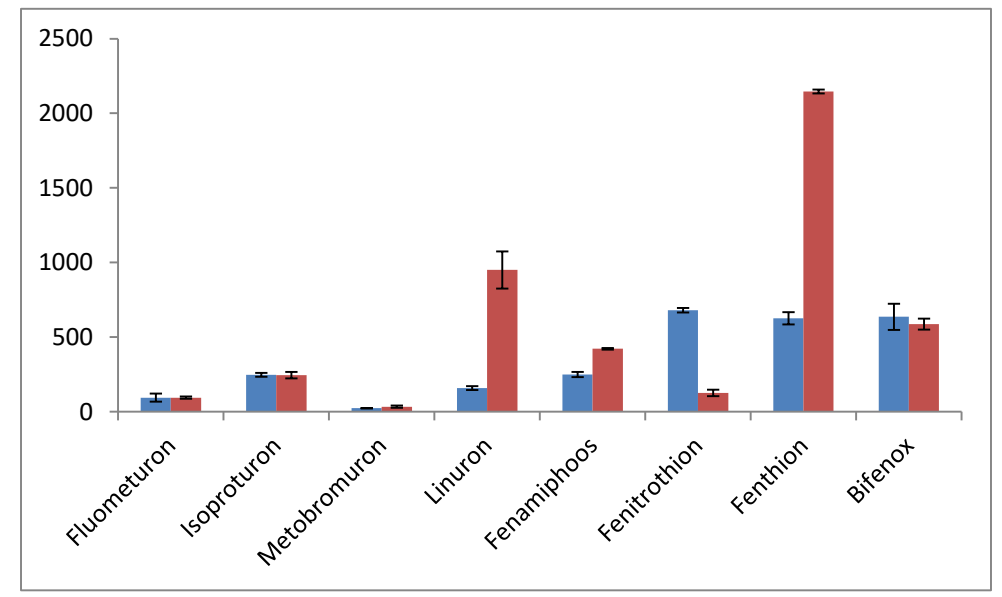

Figure 4. Comparison of the peak areas obtained with the TEOS-MTEOS coated capillaries functionalized with $\mathrm{SiO}_{2} \mathrm{NPs}$ and $\mathrm{TiO}_{2} \mathrm{NPs}$. Concentrations assayed, $25 \mathrm{ng} / \mathrm{mL}$ for linuron and $10 \mathrm{ng} / \mathrm{mL}$ for the rest of compounds.

In view of the chemical structures of the tested compounds (Table 1), the retention of the analytes on the extractive phase can be considered the result of hydrophobic, polar and, in some cases, hydrogen bonding interactions. Since all the tested compounds have similar $\mathrm{K}_{\mathrm{ow}}$ coefficients (see Table 1 ) functional groups are expected to play a key role in the extraction. In fact, the results of Figure 4 show that even compounds with very similar chemical structure exhibit quite different affinity for the two extractive phases. For example, whereas for the phenylureas fluometuron, isoproturon and metobromuron both phases provided similar extraction rates, linuron showed much stronger affinity for the $\mathrm{TiO}_{2} \mathrm{NPs}$ functionalized phase. The main difference between the latter compound and the other members of the family is the presence of an additional substituent in the aromatic ring. The presence of two contiguous substituents with partial negative charges was suggested as the reason for the strong affinity of phthalate esters for $\mathrm{TiO}_{2}$ surfaces by Banitaba et al. [18]. The reason given by the authors was that this conformation allows the establishment of mono and bidentate interactions between the negatively charged substituents and the $\mathrm{TiO}_{2}$ sites. The presence of the two electronegative halogen 
substituents in the linuron molecule would facilitate a similar interaction with the TEOS-MTEOS/ $\mathrm{TiO}_{2}$ NPs phase, thus explaining the high extraction rate found for this herbicide.

On the other hand, different studies have demonstrated the strong affinity of $\mathrm{TiO}_{2}$ for compounds containing phosphate groups $[15,19]$. The results of Figure 4 indicate that $\mathrm{TiO}_{2} \mathrm{NPs}$ are a better option for fenamiphos and fenthion. However, the extraction efficiency for fenitrothion is superior with the $\mathrm{SiO}_{2} \mathrm{NPs}$ modified phase. This can be explained by the presence of the nitro group on the analyte molecule, which facilitates their interaction with the ionized silica NPs of the coating via dipole-dipole interaction mechanism. This is in agreement with the results found for bifenox, also with a nitro substituent, as the extraction efficiency is also better with the $\mathrm{SiO}_{2} \mathrm{NPs}$ composite.

\section{Discussion}

In this work, the extraction capabilities of different commercially available capillaries (TRB 35, FFAP and PS-DVB) have been tested and compared with those of two polymeric coatings reinforced with NPs, using different pollutants with aromatic rings and Cap-LC. For the highly polar compound saccharine, the TEOS-METOS phase reinforced with NPs is the best option. This is because, besides hydrophobic interactions, the analyte can establish electrostatic interaction with the coating. For the analysis of the aromatic hydrocarbons naphthalene and fluoranthene the PS-DVB coated capillary is recommended. This capillary provided extraction rates much higher than those achieved with the other capillaries; this can be, at least, partially attributed to the thickness of the coating. A relatively high acetonitrile content in the mobile-phase was necessary for the rapid desorption and transfer of the retained analytes from the capillary to the analytical column. In principle, the specificity was also suitable for the analysis of these pollutants in environmental matrices such as water and soil extracts, but further studies would be required to optimized and validate the entire method. In this sense, substantial improvement of the sensibility can be expected by increasing the sample volume (see Figure 1). However, with this extractive capillary, the eluent composition required may be a limitation for the chromatographic separation if compounds with more than four aromatic rings (highly apolar) are going to be processed.

Although less effective for the extraction of naphthalene and fluoranthene, the TEOS-MTEOS capillary reinforced with $\mathrm{SiO}_{2} \mathrm{NPs}$ is a good alternative, particularly for compounds with functional groups capable of establishing dipole-dipole or hydrogen bonding interactions.

The number of capillaries that can be used for IT-SPME coupled on-line to Nano-LC is even more limited. In the present study, we have tested and compared TEOS-MTEOS phases modified with $\mathrm{SiO}_{2}$ or with $\mathrm{TiO}_{2} \mathrm{NPs}$. The extraction rates were highly dependent on the chemical structure of the analytes. The extraction efficiency was generally better with the $\mathrm{TiO}_{2}$ functionalized capillary for most of the tested compounds. However, the $\mathrm{SiO}_{2} \mathrm{NPs}$ showed stronger interaction with compounds having nitro groups. Both capillaries allowed the direct analysis of the tested herbicides at $\mathrm{ng} / \mathrm{mL}$, illustrating the potential of IT-SPME-Nano-LC for the analysis of organic pollutants. It has to be noted that, throughout our study, we used TEOS-MTEOS capillaries synthetized in different batches and no significant differences in their performance was found, which is in agreement with previously reported results $[8,20]$.

The results of this study may help to select the extractive phase according to the characteristics of the targeted compounds. Nevertheless, extending the study to new types of substances is still necessary, particularly in Nano-LC systems.

Author Contributions: P.G.-N. performed part of the experiments; the rest of authors designed and performed part of the experiments, analyzed the data and wrote the paper.

Funding: This research was funded by EU FEDER and the Spanish Agencia Española de Investigación (AEI)(project CTQ2017-90082-P), and the Generalitat Valenciana (PROMETEO 2016/109) for the financial support received. P. S.-M. expresses his grateful to the EU FEDER and the Spanish AEI for his pre-doctoral grant. 
Conflicts of Interest: The authors declare no conflicts of interest. The funders had no role in the design of the study; in the collection, analyses, or interpretation of data; in the writing of the manuscript, or in the decision to publish the results.

\section{References}

1. Moliner-Martínez, Y.; Herráez-Hernández, R.; Verdú-Andrés, J.; Molins-Legua, C.; Campíns-Falcó, P. Recent advances of in-tube solid phase microextraction. Trends Anal. Chem. 2015, 71, 205-213. [CrossRef]

2. Fernández-Amado, M.; Prieto-Blanco, M.C.; López-Mahía, P.; Muniategui-Lorenzo, S. Strengths and weaknesses of in-tube solid-phase microextraction: A scoping review. Anal. Chim. Acta 2016, 906, 41-57. [CrossRef] [PubMed]

3. Serra-Mora, P.; Moliner-Martínez, Y.; Molins-Legua, C.; Herráez-Hernández, R.; Verdú-Andrés, J.; Campíns-Falcó, P. Trends in online in-tube solid phase microextraction. In Comprehensive Analytical Chemistry; Elsevier: Amsterdam, The Netherlands, 2017; pp. 427-461, ISSN 0166-526X.

4. Jornet-Martínez, N.; Serra-Mora, P.; Moliner-Martínez, Y.; Herráez-Hernández, R.; Campíns-Falcó, P. Evaluation of carbon nanotubes functionalized polydimethylsiloxane based coatings for in-tube solid phase microextraction coupled to capillary liquid chromatography. Chromatography 2015, 2, 515-528. [CrossRef]

5. Moliner-Martínez, Y.; Serra-Mora, P.; Verdú-Andrés, J.; Herráez-Hernández, R.; Campíns-Falcó, P. Analysis of polar triazines and degradation products in waters by in-tube solid-phase microextraction and capillary chromatography: An environmentally friendly method. Anal. Bioanal. Chem. 2015, 407, 1485-1497. [CrossRef] [PubMed]

6. Argente-García, A.I.; Moliner-Martínez, Y.; López-García, E.; Campíns-Falcó, P.; Herráez-Hernández, R. Application of carbon nanotubes modified coatings for the determination of amphethamines by in-tube solid-phase microextraction and capillary liquid chromatography. Separations 2016, 3, 7. [CrossRef]

7. Serra-Mora, P.; Rodríguez-Palma, C.E.; Verdú-Andrés, J.; Herráez-Hernández, R.; Campíns-Falcó, P. Improving the on-line extraction of polar compounds by IT-SPME with silica nanoparticles modified phases. Separations 2018, 5, 10. [CrossRef]

8. Serra-Mora, P.; Jornet-Martínez, N.; Moliner-Martínez, Y.; Campíns-Falcó, P. In tube-solid phase microextraction-nano liquid chromatography: Application to the determination of intact and degraded polar triazines in waters and recovered struvite. J. Chromatogr. A 2017, 1513, 51-58. [CrossRef] [PubMed]

9. Jornet-Martínez, N.; Ortega-Sierra, A.; Verdú-Andrés, J.; Herráez-Hernández, R.; Campíns-Falcó, P. Analysis of contact traces of cannabis by in-tube solid-phase microextraction coupled to nanoliquid chromatography. Molecules 2018, 23, 2359. [CrossRef] [PubMed]

10. Fumes, B.H.; Silva, M.R.; Andrade, F.N.; Nazario, C.E.D.; Lanças, F.M. Recent advances and future trends in new materials for sample preparation. Trends Anal. Chem. 2015, 71, 9-25. [CrossRef]

11. Zheng, J.; Huang, J.; Yang, Q.; Ni, C.; Xie, X.; Shi, Y.; Sun, J.; Zhu, F.; Ouyang, G. Fabrications of novel solid phase microextraction coatings based on new materials for high enrichment capability. Trends Anal. Chem. 2018, 108, 135-153. [CrossRef]

12. Moliner-Martínez, Y.; Serra-Mora, P.; Verdú-Andrés, J.; Molins-Legua, C.; Herráez-Hernández, R.; Campíns-Falcó, P. Application of nanomaterials in solid and liquid microextraction. In Analytical Microextraction Techniques; Bentham Science Publishers: Emirate of Sharjah, United Arab Emirates, 2016; pp. 135-166.

13. Ahmadi, M.; Elmongy, H.; Madrakian, T.; Abdel-Rehim, M. Nanomaterials as sorbents for simple preparation in bioanalysis: A review. Anal. Chim. Acta 2017, 958, 1-21. [CrossRef] [PubMed]

14. Azzouz, A.; Kailasa, S.K.; Lee, S.S.; Racón, A.J.; Ballesteros, E.; Zhang, M.; Kim, K.-H. Review of nanomaterials as sorbents in solid-phase extraction for environmental samples. Trends Anal. Chem. 2018, 108, 347-369. [CrossRef]

15. Lin, B.; Li, T.; Zhao, Y.; Huang, F.-K.; Guo, L.; Feng, Y.-Q. Preparation of a $\mathrm{TiO}_{2}$ nanoparticle-deposited capillary column by liquid phase deposition and its application in phosphopeptide analysis. J. Chromatogr. A 2008, 1192, 95-102. [CrossRef] [PubMed]

16. Li, T.; Xu, J.; Wu, J.-H.; Feng, Y.-Q. Liquid-phase deposition of silica nanoparticles into a capillary for in-tube solid-phase microextraction coupled to high-performance liquid chromatography. J. Chomatogr. A 2009, 1216, 2989-2995. [CrossRef] [PubMed] 
17. Xu, J.; Wu, P.; Ye, E.-C.; Yaun, B.-F.; Feng, Y.-Q. Metal oxides in sample pretreatment. Trends Anal. Chem. 2016, 80, 41-56. [CrossRef]

18. Banitaba, M.H.; Davarani, S.S.H.; Pourahadi, A. Solid-phase microextraction of phthalate esters from aqueous media by electrophoretically deposited $\mathrm{TiO}_{2}$ nanoparticles on a stainless steel fiber. J. Chromatogr. A 2013, 1283, 1-8. [CrossRef] [PubMed]

19. Wang, S.-T.; Wang, M.-Y.; Su, X.; Yuan, B.-F.; Feng, Y.-Q. Facile preparation of $\mathrm{SiO}_{2} / \mathrm{TiO}_{2}$ composite monolithic capillary column and its application in enrichment of phosphopeptides. Anal. Chem. 2012, 84, 7763-7770. [CrossRef] [PubMed]

20. Silva, R.G.C.; Bottoli, C.B.G.; Collins, C.H. New silica gel-based monolithic column fort nano-liquid chromatography, used in the HILIC mode. J. Chromatogr. Sci. 2012, 50, 649-657. [CrossRef] [PubMed]

2019 by the authors. Licensee MDPI, Basel, Switzerland. This article is an open access article distributed under the terms and conditions of the Creative Commons Attribution (CC BY) license (http://creativecommons.org/licenses/by/4.0/). 